\title{
Sobre a economia política do desenvolvimento e a contribuição dos serviços
}

ANITA KON ${ }^{1}$

On the political economy of development and the contribution of services. This paper aims to ponder on recent approaches to Political Economy of Development, that bring about new concepts about the role of services activities in the economic development process. The analysis begins by checking the new attributions of services entailed by the productive paradigm changes that have occurred since the 1970's. Then, it examines the debate about the new kind of society, called "postindustrial", which is centered in the services dynamics. Finally, it discusses the relevance of social capital disponibility, as a prime factor to attain economic development

Key-words: services; development; social capital; public policies; post-industrialism

JEL classification: O00

\section{INTRODUÇÃO}

No campo da economia política, embora a avaliação sobre a contribuição dos serviços ao desenvolvimento econômico venha de longa data e já se encontrava nas obras de mercantilistas e fisiocratas, é com os clássicos que este enfoque definiu sua linha mestra, quando o foco das análises teóricas definia o trabalho na agricultura e na indústria como fonte primordial de valor. No decorrer da evolução da teoria econômica, o sistema de valores de cada conjuntura histórica, que norteou o enfoque dado às atividades de serviços, acarretou duas linhas conceituais principais (Kon, 1992: 13):

a. a marxista, segundo a qual algumas atividades, incluindo grande parte dos serviços, são improdutivas, não pertencendo ao fundo potencialmen-

\footnotetext{
${ }^{1}$ Pontifícia Universidade Católica - PUC/SP. A autora agradece ao CNPq pelo auxílio à pesquisa. E-mail: akon@terra.com.br. Submetido: outubro, 2003; aceito: setembro, 2005.
} 
te disponível para propósitos de desenvolvimento econômico; o trabalho improdutivo é mantido por parte do excedente econômico da sociedade, não se relacionando ao processo de produção indispensável; e

b. a keynesiana, segundo a qual qualquer atividade que faz jus a uma recompensa monetária é considerada útil e produtiva por definição.

No entanto, a evolução econômica mundial, grandemente impulsionada pela inovação tecnológica, particularmente após os anos 1970, tem exigido a constante reinterpretação sobre as forças determinantes deste processo de desenvolvimento. Como salienta Baran (1984), o desenvolvimento econômico significa profunda transformação, em um período, da estrutura econômica, social e política da organização dominante em uma região, com relação à produção, distribuição e consumo. No entanto, o próprio Baran, como porta-voz de uma vertente de analistas econômicos, definiu o desenvolvimento econômico "como um aumento, ao longo do tempo, da produção per capita de bens materiais" (Baran, 1984: 47). A idéia de que apenas bens materiais contribuem para o desenvolvimento continua incorporada não apenas por economistas marxianos como Baran, mas também por uma série de outros autores. Estes observam as atividades de serviços, enquanto bens imateriais, apenas como complementares às demais, e tendem a avaliá-las como "resíduo" em relação ao produto gerado de uma economia na determinação do desenvolvimento.

Este artigo tem por objetivo resgatar alguns conceitos que permitam a introdução de novas abordagens que enfocam a Economia Política do Desenvolvimento, examinando as atribuições das atividades de serviços no processo de desenvolvimento econômico recente de países de vários níveis de desenvolvimento. A pesquisa dirigiu seus esforços para uma generalização a partir dos resultados das investigações, objetivando interpretar as diferentes visões teóricas e subsidiar a reformulação dos conceitos vigentes sobre a contribuição dos serviços ao desenvolvimento econômico na atualidade.

A análise aqui empreendida é conceitual e tem seu início pela reflexão sobre as novas atribuições das atividades de serviços ante a mudança do paradigma produtivo que se delineou a partir dos anos 1970, como manifestação de uma situação mundial que já se verificava no final de 1960. São examinadas também as premissas das idéias sobre a emergência da nova forma de sociedade, conceituada como pós-industrial, que trouxe consigo a necessidade de reformulação de antigos conceitos e de nova formas de mensuração da contribuição dos setores produtivos na dinâmica do desenvolvimento. Finalmente, são examinadas, nas duas últimas partes, considerações sobre as idéias da disponibilidade do denominado "capital social" como fator primordial à dinâmica do desenvolvimento econômico, a relação com as atividades de serviços e a necessidade de incorporação destas idéias nas considerações sobre as medidas de políticas públicas governamentais na atualidade. 


\section{AS ATRIBUIÇÕES DOS SERVIÇOS ANTE A MUDANÇA DE PARADIGMA PRODUTIVO}

A partir do período em que a produção flexível, desde os anos 1970, veio gradativamente se tornando a força impulsora das transformações organizacionais e produtivas em âmbito nacional e internacional, a observação sobre atividades específicas de serviços como elementos indutores do processo de crescimento econômico ganhou conotações diferenciadas das tradicionais abordagens marxistas e keynesianas. A idéia que começou a tomar corpo mais recentemente considera que os serviços representam elementos básicos do processo industrial manufatureiro constituindo freqüentemente o fator essencial para a obtenção do sistema de produção flexível.

Como notório e amplamente discutido, este novo paradigma foi constituído como a antítese do sistema rígido inerente à produção de massa fordista, ao implicar em processos de produção e de mercado de trabalho, que englobam formas de automação da produção, mas que, apesar de serem flexíveis, são programáveis. As estruturas do mercado de trabalho resultantes são mais fluidas e as unidades de atividades econômicas em geral são mais fragmentadas, embora com fortes interconexões "insumo-produto". A gradual eliminação da integração vertical, anteriormente existente no interior das empresas, é uma das principais características da produção flexível e a parte do processo produtivo externalizada compreende, na maior parte das vezes, atividades de serviços que não constituem o foco central do processo produtivo, e em relação aos quais a razão custo/benefício da empresa com respeito à manutenção do controle se torna positiva (Kon, 1996).

Dessa forma, com a mudança dos paradigmas produtivos e organizacionais, atividades não estratégicas e auxiliares que passaram a ser externalizadas ou terceirizadas acabaram por estabelecer novos sistemas de conexão interfirma e entre firmas, que deram emergência a uma rede de pequenas e médias empresas especializadas que apoiam atividades de uma central produtiva (Coffey e Baily, 1993; Melchert, 2003). A anterior noção do paradigma fordista, sobre a firma como uma organização, passa a dar lugar à idéia de organização de firmas, enquanto que as economias de escala e de escopo internas começaram, a partir disto, a serem substituídas por economias de escala externas, criando economias de aglomeração. Salientam-se neste contexto uma gama de serviços ao produtor (producer services) que atende à demanda por insumos para a produção de outros bens e serviços, que apresentam a função de realçar a eficiência operacional e o valor da produção em vários estágios do processo produtivo (como Pesquisa $\&$ Desenvolvimento, marketing entre outros).

A flexibilização dos processos produtivos e dos mercados trouxe ainda a necessidade do processamento de uma série de informações relacionadas ao aumento da complexidade dos ambientes externos e internos às empresas, bem como da competitividade nacional e internacional associada à agilização e constância da renovação destas informações (Kon, 2003: 187). 
Assim, o crescimento destes serviços auxiliares tem sido amplamente condicionado por alguns fatores como:

i) o aumento da inovação e da diferenciação do produto, para o qual concorrem atividades de $\mathrm{P} \& \mathrm{D}$, planejamento, publicidade, e serviços de distribuição da produção;

ii) a nova forma pela qual os produtos são produzidos, que englobam novas tarefas, funções e técnicas tanto na organização quanto do processo produtivo, de modo a aumentar a eficiência e a permitir rápidos ajustamentos às mudanças econômicas ocorrentes. Particularmente a mudança tecnológica exigiu a assessoria de firmas especializadas nos campos da informação, engenharia industrial, processos de planejamento e de pesquisa;

iii) o novo ambiente financeiro e de distribuição do produto vem se tornando cada vez mais complexo, ao envolver a necessidade de levantamentos de fundos, manutenção de relacionamentos internacionais, adaptação a fusões, exploração de novos mercados e mesmo da administração de escritórios em outros territórios;

iv) as políticas governamentais internas e externas voltadas à regulação e estimulação de mercados vêm exigindo o apoio de especialistas que conheçam as formas de contemporizar o atendimento das normas de intervenção governamental, com as necessidades de continuidade dentro dos novos parâmetros;

v) o crescimento das transações interfirma e entre firmas mencionado exige o aumento da capacidade e da complexidade de técnicas administrativas e gerenciais, que determinem as escolhas estratégicas, os planos, e que coordenem e controlem as conexões entre todos os níveis de relacionamentos (Coffey e Baily, 1993: 859). Essa gama de necessidades envolve a participação de especialistas de várias áreas de serviços (advogados, economistas, engenheiros, publicitários, sociólogos e consultores, entre outros) que sirvam de apoio às tomadas de decisões em um ambiente de constantes transformações.

A tecnologia da informação transformou as economias de muitas maneiras. Primeiramente, o que é produzido ou a composição ("mix") de produtos tem sido alterado, de modo que existe uma crescente complementaridade entre bens e serviços, com o desenvolvimento de novos serviços e maior diferenciação de produto ao invés de produção em massa. Em segundo lugar, o mercado tem mudado abarcando maior internacionalização e uma crescente comercialização de serviços. Outra razão é que a localização da produção dos serviços tem se modificado, incluindo também a internacionalização e finalmente tem ocorrido uma transformação dos processos produtivos (Ochel e Wegner, 1987).

\section{A CONTRIBUIÇÃO DOS SERVIÇOS NAS TEORIAS DO PÓS-INDUSTRIALISMO}

As mudanças significativas pelas quais passaram as economias avançadas na década de 1970 incluíram, entre outros aspectos, particularmente: i) a elevação 
da internacionalização das atividades econômicas; ii) a reorganização das firmas dominantes; iii) a crescente integração da indústria manufatureira com a de serviços; iv) uso crescente da tecnologia microeletrônica; v) a demanda crescente na indústria por uma força de trabalho mais qualificada, porém com muitos trabalhos rotineiros sendo eliminados pela mudança tecnológica; vii) a crescente complexidade e volatilidade do consumo; viii) uma mudança no papel da intervenção governamental.

As idéias teóricas iniciais a respeito da sociedade pós-industrial surgiram concomitantemente com as primeiras tentativas de mudanças do paradigma de processo produtivo do taylorismo para processos mais flexíveis. Estas transformações foram interpretadas como uma modificação da sociedade fordista baseada na produção e consumo de massa em grande escala e apoiada pela demanda dos gastos governamentais para o gerenciamento de suas funções administrativas e da Previdência e Saúde (principalmente nas nações mais avançadas em que prevalecia o welfare state). Como intensamente discutido na literatura, as formas pós-fordistas de produção emergiram desde os anos 1970, quando a indústria passou a utilizar a nova tecnologia e processos organizacionais flexíveis, que incorporavam processos just in time (produção sem estoques) inspirado na filosofia japonesa do kanban (só repor o que for consumido).

Estes processos acarretaram uma intensificação do progresso tecnológico e de mudanças organizacionais, com reflexos consideráveis sobre a divisão, organização e qualificação do trabalho, do produto e do consumo. Requeriam força de trabalho capaz de ser integrada a múltiplos aspectos da produção, para responder mais rapidamente às mudanças do mercado e à competição internacional. Novas formas de governo, que se retirava de funções empresariais e restringia suas funções produtivas, passaram a apoiar a iniciativa privada e a pesquisa tecnológica, em países mais avançados (Coriat, 1994; Marshall e Wood, 1995).

Nesse processo, o papel assumido pelos serviços ganharia peso considerável na alavancagem do desenvolvimento. A visualização das transformações que ocorreriam nas sociedades através da ênfase em atividades de serviços começou a ser delineada primeiramente através de uma abordagem sociológica (Touraine, 1969). Porém, na década de 1970, novas interpretações sobre o desenvolvimento do setor de serviços e a sociedade pós-industrial centralizaram a literatura econômica mundial a respeito do desenvolvimento, enfocando mudanças de conceitos e a necessidade de renovação das classificações destas atividades ${ }^{2}$ (Kon, 1996 e 2004).

Convém observar, como salientam Castells e Aoyama (1994), que as primeiras idéias sobre a sociedade pós-industrial foram concebidas quando ainda não havia sido inventado o microprocessador (1971), o computador pessoal (1974) e o método de recombinação do DNA (1973). Dessa forma, os efeitos mais inten-

${ }^{2}$ Nesse contexto, destacaram-se como expoentes as idéias de Katouzian (1970: 362-82), Bhalla (1970: 519-39), Bell (1967), Gershuny (1977), Hill (1977) e Browning \& Singelmann (1978). 
sos do progresso tecnológico ainda estavam por vir. As principais premissas da teoria do pós-industrialismo, na época, estipulavam que:

i) a geração de conhecimentos é a fonte da produtividade e do crescimento e se estende por todos os domínios da atividade econômica, através do processo de informação;

ii) a ênfase da atividade econômica mudaria da produção de bens para fornecimento de serviços. A eliminação do emprego agrícola seria seguida pelo declínio irreversível dos trabalhos manufatureiros, em benefício das ocupações em serviços, que constituiriam a maior proporção do emprego. À medida do avanço econômico dos países, o emprego e a produção seriam cada vez mais focados nos serviços, sendo os demais setores complementares;

iii) a nova economia aumentaria a relevância das ocupações com alto conteúdo de informação e conhecimento. As ocupações administrativas, de profissionais liberais e técnicas cresceriam mais rapidamente do que outras categorias ocupacionais e constituiriam o núcleo da nova estrutura social.

Uma visão crítica inovadora sobre a sociedade pós-industrial é desenvolvida por Gershuny (1977), ao mostrar que a definição dos serviços pode se referir à natureza do produto ou às características do trabalho e, apresenta, dessa forma significados diferenciados. Com relação à natureza do produto, um bem é definido como material e mantém sua existência após sua produção ou consumo, enquanto que um serviço é imaterial e se esgota no momento de sua aquisição ou consumo. Uma necessidade pode ser satisfeita através de um bem ou de um serviço, como, no exemplo do autor, a lavagem de uma camisa por uma máquina de lavar ou pelos serviços de uma lavadeira ou lavanderia. Por outro lado, o trabalho em serviços pode ser definido como emprego em uma indústria cujo produto final é um produto não-material.

Esse autor critica a visão simplificada de que a economia de serviços se baseia no modelo simples em que as novas "necessidades pós-industriais", abstratas e sofisticadas, requerem um aumento da provisão de serviços e conduzem ao crescimento do emprego terciário e cada vez mais à era pós-industrial. Gershuny salienta que desde a década de 1950, existem evidências de que essas necessidades, anteriormente satisfeitas por serviços, vêm sendo substituídas por bens. Em segundo lugar, o crescimento do emprego nos serviços não significa necessariamente que o consumo de bens industriais tenha decrescido relativamente e, por outro lado, é possível dizer que o nível de consumo de serviços não explica adequadamente o nível de empregos terciários.

Melhor explicando, segundo Gershuny, o crescimento dos serviços pode ser considerado simplesmente como uma manifestação de alterações na divisão do trabalho à medida do progresso tecnológico e, da criação de indústrias de serviços (de distribuição, bancários e financeiros) e das ocupações de serviços (administradores, tecnólogos e outros profissionais), cujas atividades melhoram a eficiência do sistema produtivo. Já nos anos 1970, o autor salientava que novas relações de trabalho tenderiam a se estabelecer na sociedade pós-industrial: a) a produção final ocorreria cada vez mais em casa, enquanto o trabalho fora de ca- 
sa seria dedicado à produção intermediária de bens; b) o emprego fora de casa seria crescentemente relacionado ao planejamento e programação da produção.

No entanto, a tese da economia de serviços que se desenvolveria automaticamente à medida do desenvolvimento da sociedade não parece ao autor fadada a acontecer e, se for desejável, este caminho deveria ser promovido, pois as soluções para as necessidades da sociedades podem ser cumpridas através de várias alternativas técnicas ou sociais, que implicam em diferentes substituições de capital por trabalho. O discurso de Gershuny, que salientava ainda a contribuição de algumas ocupações de serviços à produtividade de outras atividades, não foi capaz de mudar o pensamento convencional na época.

No entanto, o mesmo autor salienta que embora as sociedade se dirijam para o crescimento do setor de serviços, alguns economistas questionam a elevação do consumo de serviços, enfatizando que as estatísticas mostram o declínio das compras de serviços pelos consumidores das famílias como proporção dos gastos totais nas últimas duas ou três décadas, particularmente em países em desenvolvimento (Gershuny, 1990). Explicam este fenômeno como decorrente do que é denominado como um processo socio-técnico, o cost disease, ou seja, tendo em vista o crescimento da produtividade do trabalho no setor manufatureiro, os salários tendem a crescer neste setor, como recompensa pelo valor agregado excedente gerado. Por outro lado, existe um processo de barganha coletiva por igualação de salários da economia, que atinge o setor de serviços pelo argumento da equidade. No entanto, a produtividade deste setor não se eleva com a mesma velocidade e montante do setor manufatureiro, e o financiamento da elevação dos salários é repassado aos preços dos serviços. Este processo leva portanto ao encarecimento proporcional dos serviços e à diminuição da demanda por produtos do setor, que são substituídos pelo “auto-serviço”, quando existir esta possibilidade. Embora este processo de crescimento relativo dos custos dos serviços não seja inevitável, parece existir uma forte tendência de crescimento dos preços dos serviços de consumo familiar (Kon, 2003: 191).

A visão acima é considerada como pessimista pelos pesquisadores que observam as vantagens relativas e os benefícios das economias de serviços como, por exemplo, a melhor resistência às mudanças cíclicas da economia que podem ocasionar fases críticas de desenvolvimento, desde que, de um modo global, os serviços não demandam tantos investimentos em ativos fixos, ou em estoques, que podem deprimir os preços e causar perdas durante recessões econômicas.

Um outro conceito consideravelmente divulgado é proposto por Hill (1977: 318), que em um artigo ressalta a necessidade de melhor conceituar a natureza dos produtos, para fins de análise, no que se refere às atribuições das atividades produtivas no contexto do processo de transformação econômica. Com este objetivo, propõe novas interpretações conceituais, que classificavam bens e serviços em categorias lógicas distintas para efeito de produção e consumo. Enquanto um bem é um objeto físico apropriável e transferível entre unidades econômicas, um serviço é definido como um fenômeno não-físico que proporciona uma mudança na condição de uma pessoa ou de um bem pertencente a uma unidade econômi- 
ca. O processo de produzir um serviço é a atividade que afeta a pessoa ou os bens, enquanto que o produto é a mudança na condição da pessoa ou do bem afetado.

Este autor defende a idéia de que os serviços não são "bens imateriais”, porém como não são usualmente transferíveis de uma unidade econômica a outra, não se ajustam à teoria sobre modelos de troca pura tipo walrasiano, em que os bens são comercializáveis entre unidades econômicas. Considera ainda que as peculiaridades dos bens e dos serviços não poderiam ser determinadas pela tecnologia empregada, que pode ser a mesma para a produção e para a reparação de um bem; também não são distinguidos pela diferença de durabilidade, desde que os serviços podem ser considerados permanentes ou irreversíveis, pois muitas vezes a mudança que ocasionam em certos bens é tão durável quanto o bem, como, por exemplo, certos serviços de reparação de veículos, programas de software para computadores ou serviços técnicos advocatícios.

Assim, a característica de durabilidade e de transportabilidade, nem sempre se ajusta perfeitamente à definição de um bem ou serviço, pois além de serem extremamente duráveis, certos serviços são transportáveis, como no caso do software; outros serviços são transportáveis via aérea ou por telecomunicações, como é o caso de serviços de consultoria legal, engenharia, e administração. Hill salienta também que uma mesma atividade, como a pintura, por exemplo, pode ser classificada como produção de bens ou de serviços, dependendo da organização do processo de produção entre diferentes unidades.

$\mathrm{Na}$ literatura mundial, a noção de pós-industrialismo desenvolvida no período trazia a mensagem sociológica e política de que o capitalismo havia sido substituído pela sociedade pós-industrial. Esta proposição não distinguia entre as implicações sobre as forças de produção (industrialização) e as relações de produção (capitalismo) e nem entre as relações de classe e a divisão de trabalho. Críticos desta visão salientavam que a nova sociedade continuava baseada no capitalismo, embora a participação da produção imaterial ganhasse peso relativo. Walker (1985: 45) mostra que as mudanças na divisão do trabalho na sociedade pós-industrial podem ser compreendidas a partir da teoria do desenvolvimento capitalista. Assim, os produtos, as atividades e os tipos de trabalho podem se transformar no tempo, mas a proposta da teoria do capitalismo permanece váli$\mathrm{da}$, pois estas mudanças se destinam à maior geração e acumulação do valor excedente produzido, ou na linguagem marxista "mais-valia".

As discussões sobre a contribuição dos serviços ao valor agregado — visando a avaliação das transformações do peso destas atividades no decorrer da passagem de uma economia para o pós-industrialismo - trouxeram a observação de que a necessidade do aperfeiçoamento dos conceitos tradicionais possibilitaria a mensuração mais adequada dos novos fenômenos advindos das transformações econômicas. Os antigos conceitos passaram a ser questionados a partir das mudanças nos paradigmas de produção, porém a adaptação à nova realidade não aconteceu rapidamente.

Walker criticava determinados conceitos sobre a definição do que deveria ser considerado um bem material ou serviço e sua classificação em setores. Menciona 
o exemplo de um restaurante, que fornece um produto conjunto correspondente à indústria (fabricação da refeição) e a serviços (atendimento do cliente). Porém, no caso da eliminação do serviço em favor da produção em massa, como no caso do McDonald's e outros restaurantes de fast food, seria um absurdo alocar esta produção no setor de serviços, pois o processo produtivo indica uma forma industrial de preparação do alimento (Walker, 1985: 48). Na realidade, o processo de produção em massa em caráter industrial correspondente ao fornecimento de serviços, será posteriormente reconhecido na literatura como incluído na "Indústria de Serviços" do setor terciário da economia, como já havia sido conceituado pela ONU (1968) em seu A System of National Accounts, onde eram definidas formas de mensuração do valor gerado por estas atividades (Kon, 1992).

A evolução tecnológica estimulada ou estimulando as mudanças do paradigma produtivo, trouxeram consigo a percepção mais aguçada sobre o papel dos serviços de informação e comunicação no processo de desenvolvimento. As análises incluídas no corpo teórico voltado à área da economia na teoria da informação, também trazem a preocupação sobre as conceituações adequadas que permitam a valoração empírica deste fenômeno (Kon, 2003: 190). Segundo esta teoria, a informação não é um fenômeno abstrato flutuante, porém é diretamente relacionada ao conhecimento prático, à organização da produção e ao consumo, ou seja, à ação do trabalho e, portanto, está incorporada em todos os produtos do trabalho. O conteúdo da informação está nos dois lados da fronteira entre bens e serviços. O valor de uso de alguns bens materiais está implicitamente ligado à forma de utilização da informação, como no caso dos computadores, que detêm a capacidade de armazenar, transferir e interpretar a informação, mas que devem ser carregados com programas (softwares). Assim, o produto gerado por um trabalho de serviços pode ser material, ou materializado em um bem em alguns casos.

O caso do programa de computador que toma a forma eletrônica em um disco se inclui entre uma série de outros produtos que apresentam forma material (livros e outras publicações, etc.), embora sua existência se deva a um trabalho intelectual de serviços. A natureza física do bem resultante leva grande parte dos analistas a considerá-lo como bem material, enquanto que a manipulação sofisticada do programa para ser posto em uso na produção através da via eletrônica, caracterize o produto como resultado dos serviços de computação. De fato, a consideração de que têm uma forma tangível e discreta traz a consideração da distinção que pode haver entre bens "tácteis" e "não-tácteis", conforme Walker (1985: 51). Este autor salienta que os aspectos informacionais de determinados bens têm se intensificado no tempo, e o valor de uso, incorporado no conteúdo da informação, deve ser enfatizado na determinação da contribuição dos serviços ao desenvolvimento, apesar da materialidade que envolve os objetos que os contêm.

Uma questão relevante que começou a ser analisada na literatura sobre a sociedade "pós-industrial" se refere à classificação a ser dada sobre a natureza do produto, quando é considerada a divisão de trabalho dentro de processos de pro- 
dução complexos e diversificados, onde alguns insumos intermediários são considerados em blocos isolados como bens ou como serviços. Dessa forma, sua contribuição ao desenvolvimento pode ser avaliada tanto como pertencente à indústria quanto ao setor de serviços. Constituem o caso dos serviços do produtor (producer services), que podem ser insumos intermediários na produção de bens, como serviços de consultoria de profissionais liberais contratados para o planejamento em uma indústria. Observe-se que toda a produção de bens inclui o consumo intermediário de serviços e toda produção de serviços inclui insumos materiais (Kon, 1996).

No entanto, esta questão não diz respeito apenas à diferenciação ou especialização da divisão de trabalho dentro do processo produtivo, como defendido por Walker. Na atualidade, a intensificação do peso dos insumos de serviços na produção de bens materiais leva à necessidade de avaliação do componente predominante na produção, quando se trata da análise do papel destes setores para o desenvolvimento econômico. A avaliação do peso destes insumos na geração do valor adicionado pela produção pode levar a impactos muitos diferenciados na matriz insumo-produto da economia e nas conclusões analíticas sobre determinantes do desenvolvimento. Para alguns autores como Gershuny, a forma de lidar com estas análises seria considerar no peso da matriz insumo-produto a contribuição ao valor adicionado de categorias ocupacionais dentro do processo produtivo, separando-se as ocupações de serviços, das puramente industriais ou agrícolas. Esta prática, no entanto, ainda permanece no plano teórico dadas as dificuldades operacionais.

A partir de um enfoque diferenciado, a contribuição dos serviços ao desenvolvimento econômico pode ser avaliada pela capacidade de proporcionar a circulação de mercadorias ou outras utilidades. Neste sentido, a mercadoria é considerada pelos analistas como qualquer produto do trabalho vendido no mercado em troca de dinheiro, seja em forma de bens ou serviços. Melhor definindo, a mercadoria pode ser avaliada tanto através de produtos úteis quanto da incorporação de valor, ou seja, uma medida do tempo de trabalho abstrato envolvido em sua produção. A circulação envolve fluxos de valores e de valores de uso. Assim, a circulação de mercadorias através de comércio, transportes, de atividades financeiras (no caso de mercadoria-dinheiro), ou de informações e comunicações, tem a função de permitir a complementação do ciclo produção-distribuição-consumo da economia, que efetiva o processo dinâmico de desenvolvimento econômico. Porém, o mercado não é o único modo de circulação de valores (Gershuny, 1977; Stanback, 1979; Walker, 1985) e, portanto, outras formas de circulação que não passam pelo mercado também devem ser levadas em conta na avaliação, como as trocas interfirma e fornecimento de serviços pela área pública. 


\section{DESENVOLVIMENTO ECONÔMICO, CAPITAL SOCIAL E SERVIÇOS: O PAPEL DAS POLÍTICAS PÚBLICAS}

Uma discussão recente que vem se ampliando na área da Economia Política do Desenvolvimento refere-se à importância do capital social como base para o ambiente favorável a este processo. As análises mais recentes concluem que as condições descritas nos modelos de desenvolvimento neoclássicos (alocação eficiente dos recursos), keynesianos e kaleckianos (relevância da demanda efetiva) ${ }^{3}$ ou schumpeterianos (dinamismo da oferta, da introdução da inovação tecnológica, ou da organização interna das firmas para o aumento da competitividade e geração de expansão comercial), não são suficientes para explicar a continuidade do processo e do ritmo de crescimento dos países.

A partir da observação das condições de desenvolvimento de países mais avançados tem sido observada uma série de condicionantes inerentes aos ambientes sócio-econômicos dos países, na atualidade, que dizem respeito à disponibilidade do denominado capital social para a concretização dos objetivos de crescimento. As condições para a estruturação do capital social vêm sendo discutidas através de análises teóricas, bem como têm sido introduzidas nas agendas de debates dos planejadores públicos e dos organismos de fomento, com o objetivo de fornecer subsídios às políticas públicas de desenvolvimento aos países menos avançados.

Embora o conceito de capital não seja novo e tenha se originado nas áreas das ciências sociais e da antropologia, ${ }^{4}$ as relações sociais, tipos de intercâmbios sociais e de comportamentos solidários vêm sendo incorporados nas análises de economistas, que observam nestes elementos um papel preponderante para a consecução de estímulos econômicos ao desenvolvimento, valendo-se de um paradigma interdisciplinar - no nível microeconômico, isto é, observado primeiramente através da maneira pela qual o capital social melhora o funcionamento dos mercados. No nível macroeconômico, o papel das instituições, das estruturas legais e do governo na organização da produção é considerado como impactante sobre o desempenho macroeconômico.

No nível macro, o capital social se torna a quarta categoria de capital da função produção (capital físico, natural e humano). Em recentes pesquisas, sua contribuição ao desenvolvimento econômico, ao investimento ou à equidade tem sido avaliada através de duas etapas. Uma primeira aproximação é obtida a partir de modelos de função produção relacionada às contas nacionais que explicam

\footnotetext{
${ }^{3}$ Entre estes se destacam os modelos de Harrod (incorporando as expectativas empresariais na função investimento), Dommar (relevância das taxas constantes de crescimento dos investimentos) e Kaldor (papel das taxas de lucros elevadas e da distribuição de renda que gerem maior propensão global a poupar, como estimulantes do crescimento).

${ }^{4}$ Em estudos de Durkheim, Marx e dos antropólogos Raymond Firth, Marcel Mauss e George Foster (CEPAL, 2002).
} 
o crescimento do PIB como função do crescimento do trabalho, capital e tecnologia. O resíduo obtido após a contabilidade do capital físico e natural inclui o capital humano e social. Na segunda etapa é necessária a separação destes dois últimos agregados, que só é possível se o valor do capital humano, for estimado o que ainda não foi feito com sucesso, mas existem registros de pesquisas nesse sentido (Grootaert, 1998: 16).

As definições e nuances do conceito e da aplicação do capital social passam por um amplo contexto de interpretações. Bourdieu (1985) define este capital como um conjunto de recursos reais ou potenciais a disposição dos integrantes de uma rede durável de interrelações mais ou menos institucionalizadas. Coleman (1988 e 1990) o interpreta como sendo parte dos recursos sócio-estruturais que constituem um ativo de capital para o indivíduo e facilitam certas ações comuns dos que constituem esta estrutura. Por outro lado, Putnam (1993) salienta os aspectos das organizações sociais, entre as quais as normas coletivas, as redes e o espírito de confiança que contribuem para facilitar a cooperação no sentido de proporcionar ações de benefício mútuo. Para este autor, o capital social incrementa os resultados do investimento em capital físico e humano. Ele considera um conjunto de "associações horizontais" entre indivíduos que facilitam a coordenação e cooperação de seus membros, com finalidade de benefício mútuo. Uma visão baseada na teoria institucionalista (North 1990; Olson, 1982), discute o papel das estruturas e relações institucionais como governo, regime político, regras legais, sistema judiciário e outros, como representativos do capital social que influencia o desenvolvimento sócio-econômico das sociedades.

As principais instituições internacionais de fomento têm considerado em suas decisões de auxílio os reflexos de investimentos no capital social dos países em desenvolvimento. Dessa forma, estudos para o Banco Mundial de Woolcock (1998) e Dasgupta e Serageldin (1998) ressaltam a importância de estimular o investimento a nível micro e macro na capacidade organizativa, através de instituições, relações, atitudes e valores que determinam a interação interpessoal e facilitam o desenvolvimento econômico e a democracia. Em suas análises, o Banco distingue entre capital natural do país (recursos naturais), capital construído gerado pelo ser humano (infra-estrutura, bens de capital, capital financeiro, comercial, etc.), capital humano (graus de nutrição, saúde, educação da população) e capital social (instituições, relações e normas das inter-relações sociais da sociedade).

O Banco Interamericano de Desenvolvimento (Kligsberg, 2000) mostra a relevância do capital social, conceituando-o como incluindo normas e redes que facilitam a ação coletiva e contribuem para o benefício comum. Propõem o estímulo à análise e discussão dos desafios do desenvolvimento de cada país, através da formação de redes de centros de pesquisa acadêmica e outros, para gerar e difundir o conhecimento através de meios de comunicação em massa, além de promover uma integração de programas sistemáticos de ensino que favoreçam o capital social.

Por sua vez, o Programa das Nações Unidas para o Desenvolvimento - 
PNUD (Lechner, 2000), incentiva a ampliação de programas que estimulem relações informais de confiança e cooperação (entre famílias e colegas), a associatividade formal em organizações de diversos tipos e uma rede institucional normativa que fomente estas relações. No entanto, o PNUD chama a atenção para a dificuldade de mensuração adequada para os resultados destas interrelações.

Adicionadas a estas várias conceituações e visões, observações empíricas têm constatado efetivamente o impacto no desenvolvimento econômico, com relação a crescimento, maior eqüidade e diminuição de pobreza. Inúmeras pesquisas empíricas vêm aperfeiçoando a metodologia de mensuração de indicadores qualitativos e quantitativos do capital social. A observação generalizada aponta para a constatação de que não apenas a disponibilidade de capital social afeta favoravelmente os resultados do mercado e macroeconômicos, como também de que sua ausência bloqueia e atrasa o impacto ao desenvolvimento (Fukuyama, 1995; Grootaert, 1998: 10; Knack e Keefer, 1996).

Os principais instrumentos de ação constatados como determinantes destes impactos são a informação compactuada, a coordenação das atividades e a tomada de decisão coletiva. Embora não remova completamente a incerteza, a informação compactuada cria o conhecimento sobre a forma pela qual os diversos agentes respondem a diferentes situações; atua como mecanismo para assegurar que as expectativas sobre a conduta mútua são de fato realizadas, o que reduz os custos de transação. Por sua vez, a falta de coordenação das atividades conjuntas pode levar a falhas de mercado, enquanto que a tomada de decisão coletiva é uma condição necessária para a provisão de bens públicos e o gerenciamento de externalidades nos processos produtivos.

A nova visão sobre a relevância do capital social introduzida nas análises econômicas da atualidade enfatiza a aplicabilidade destes conceitos através da intervenção estatal ou privada, como subsídios ao desenvolvimento. A proposição expressa é de que potencializando os elementos concretos e abstratos do capital social, é possível incrementar a participação dos agentes econômicos e sociais para a resolução de obstáculos que implicam em bloqueios ou retardamento da dinâmica do desenvolvimento (Miranda e Monzó, 2003). Os efeitos deste capital constituem externalidades incluídas entre as economias externas auferidas entre agentes econômicos. Da mesma forma que a maior disponibilidade pode trazer vantagens a regiões e países, a carência amplia as assimetrias de conhecimento, informação ou outras que acarretam disparidades de desenvolvimento. Dessa forma, o capital social pode ser utilizado pelo indivíduo ou pelo grupo, de forma estratégica para a acumulação de novos recursos produtivos ou outros tipos de capital (físico e financeiro), seja com reflexos positivo na eliminação das disparidades, seja de modo negativo marginalizando ou excluindo os menos dotados.

A relação direta entre o aumento do capital social e as ocupações e atividades de serviços é visualizada através da materialização da idéia abstrata conceituada de cooperação, reciprocidade e confiança, através de serviços de assessoria de várias ordens. Estes serviços, a serem disponibilizados tantos pela esfera pú- 
blica quanto privada, referem-se a uma rede de instituições de pesquisa, planejamento, informação, educação, treinamento, comercialização, entre outros. Proporcionam o manejo administrativo e de recursos, condições ambientais favoráveis, conhecimentos sobre aspectos legais, coordenação entre etapas de trabalho entre vários agentes, favorecimento de apoio à produção, distribuição e consumo de forma associativa. Os serviços de apoio ao fortalecimento do capital social incluem o apoio técnico à produção, aos vínculos entre os agentes produtores e consumidores, entre dirigentes e funcionários, bem como à organização e planejamento das redes de assessoria.

Particularmente, pequenas e microempresas bem como trabalhadores autônomos se beneficiam dos serviços destinados ao aumento do capital social, embora as externalidades resultantes sejam apropriadas também pelas médias e grandes empresas que já dispõem de uma rede organizada de apoio. A articulação econômica eficiente entre agentes internos e externos de uma sociedade também constitui um reflexo da disponibilidade do capital social.

O conceito de capital social vem sido utilizado nos programas de superação da pobreza propostos pela intervenção governamental em sociedades em desenvolvimento. As políticas sociais definidas pelos governos de países menos desenvolvidos incluem o fornecimento de serviços que proporcionam condições de ampliação dos elementos constitutivos do capital social como: reciprocidade entre agentes, intercâmbio e solidariedade, controle social da distribuição de recursos, apoio familiar e extra-familiar. No combate à pobreza, o chamado capital social comunitário complementaria de diversas formas os serviços públicos, - atuando também em redes sociais que não passam pelo mercado, - ao articular os serviços públicos com os receptores diretos dos benefícios sociais, aumentando a participação mediante sua incorporação ativa ao processo econômico. Por outro lado, tornaria mais eficazes os programas de fomento às microproduções urbanas e rurais (de empresas e autônomos).

As experiências realizadas em alguns países de fortalecimento do capital social através de serviços públicos revelam que os resultados mais eficazes acontecem através da atuação no entorno local e regional especificamente, diretamente aos que usufruem da construção e gestão da infra-estrutura social, quando é assegurado que os benefícios dos programas cheguem efetivamente aos destinatários (Miranda e Monzó, 2003). Como salientam estas autoras, para a utilização do capital social como uma ferramenta para pensar e superar a pobreza - através de uma abordagem em que atuam tanto os agentes estatais quanto os usuários dos serviços públicos - é necessário a politização da análise do capital social. A funcionalidade e a instrumentalização do capital social para os programas de desenvolvimento devem passar pela articulação com os elementos políticos da sociedade, visando a superação dos conflitos e interesses individuais.

Essa politização implica no esforço do direcionamento das medidas de fomento ao capital social para que contribuam a uma maior integração social e não à exclusão e alheamento do indivíduo das correntes econômicas atuantes que tendem a perpetuar os vínculos frágeis de alguns agentes com instituições normativas. 
Segundo Miranda e Monzó, as políticas públicas, neste sentido, atuam em uma interface ou área de intercâmbio, entre os agentes institucionais, organizacionais ou cívicos e a comunidade. Esta interface se dá entre quatro sistemas complexos, o da administração estatal, o do mercado, o dos partidos políticos e o das comunidades populacionais. Os intercâmbios de informação, serviços e bens ocorrem tanto nos ambientes mais favorecidos quando nos mais desfavorecidos e excluídos. Esta forma de visão propõe uma abordagem inovadora da intervenção do Estado, de modo a propiciar um espaço de negociação em que cada ator desenvolva um potencial para melhor se situar na interface através das redes de apoio, capacidades de autogestão, contatos institucionais, sistemas de cooperação e práticas pessoais e partidárias.

O que se tem observado em países menos desenvolvidos é que a atuação das políticas públicas, nesta interface, tem gerado uma dinâmica divergente entre os atores do sistema comunitário e estatal, que vem gerando implicações negativas, como falta de sinergia, tecnocracia burocrática ineficiente, impossibilidade de competitividade no mercado, clientelismo partidário e exclusão.

\section{CONSIDERAÇÕES FINAIS}

A evolução das idéias teóricas sobre os serviços como exercendo um papel relevante no processo de desenvolvimento econômico tomaram impulso maior desde os anos 1970. A partir da evolução econômica mundial nas áreas da produção, distribuição e aquisição de bens e serviços, novos conceitos e metodologias de mensuração surgiram, ante a necessidade de avaliação mais adequada do fenômeno.

A reestruturação na composição das atividades produtivas das economias de diferentes níveis de desenvolvimento foi associada à velocidade e ao grau de inovação tecnológica nos processos produtivos e organizacionais, principalmente ligados ao setor de serviços, mais especificamente nos campos da telemática, e outros processos de telecomunicações, serviços de informática, relacionados à transferência de informação e conhecimento. Além disso, a relevância dos serviços no comércio internacional foi observada através da experiência tanto das economias modernas como das menos avançadas, bem como o impacto sobre o desenvolvimento local e regional destas economias. Estas transformações regionais levaram recentemente a um modelo teórico diferente de influências econômicas baseadas em lugares-centrais distintos ou distintos pólos de crescimento em uma mesma região, ao invés da anterior teoria sobre um único lugar-central.

Discussões recentes enfatizam a relevância do capital social para a consecução do desenvolvimento econômico e, assim, a materialização deste capital através de serviços públicos e privados representa um determinante básico para as condições de competitividade na atualidade. Por outro lado, tais condições são um pré-requisito para o desenvolvimento e não apenas um resultado ou um produto final. Assim, sua provisão adequada torna-se então um elemento crucial da 
dinâmica do processo de desenvolvimento das economias. Neste sentido, os serviços governamentais desempenham um papel fundamental em países menos avançados, seja através do fornecimento de bens públicos, ou da complementação da provisão privada de serviços de mercado, a fim de fornecer uma infra-estrutura, serviços educacionais e de saúde, que preparam a economia para o caminho da modernização econômica. Os conceitos de "capital social" incorporado em uma série de serviços a serem oferecidos por agentes estatais ou privados estão sendo gradativamente incorporados às análises governamentais como subsídio para o direcionamento das políticas públicas.

A literatura mostra que as atividades de serviços não são apenas dependentes da demanda de atividades manufatureiras, pois mantêm transações com todas classes de atividades econômicas e detêm áreas próprias de mercado que se estendem além da localidade em que se inserem, incluindo mercados internacionais. A contribuição dos serviços no desenvolvimento das economias tem características diferenciadas em países mais avançados ou em desenvolvimento, porém é fundamental em qualquer nível de desenvolvimento, ao tornar-se a maior fonte de geração de empregos na atualidade.

As idéias apresentadas neste artigo pretendem mostrar a forma pela qual foram transformados alguns mitos conceituais que prevaleceram por longo tempo no contexto da economia política, acerca da função dos serviços nos processos produtivos e na dinâmica global das economias, enquanto participantes nos processos de reestruturação econômica e social.

\section{REFERÊNCIAS BIBLIOGRÁFICAS}

BHALLA, A . S., "The role of Services in Employment Expansion”, International Labour Review, $101,1970$.

BARAN, P., A economia política do desenvolvimento. S. Paulo. Abril Cultural, 1984.

BELL, Daniel, "Notes on the post-industrial society (II)", Public Interest, n. 7, Spring 1967, pp. $102-$ 18.

BOURDIEU, Pierre, "The forms of capital", Handbook of the Theory and Research for the Sociology of Education, New York. John Richardson, 1985.

BROWNING, Harley L. \& SINGELMANN, Joachim, "The Transformation of the U.S. Labor Force: the Interaction of Industry and Occupation", Politics and Society, 8, (3-4), 1978, pp. 481509.

CASTELLS, Manuel e AOYAMA, Yuko, "Paths Towards the Informational Society: Employment Structure in G-7 Countries, 1920-90”, International Laborur Review, 133 (1), 1994, pp. 5-33.

CEPAL, "Capital social: sus potencialidades y limitaciones para la puesta en marcha de políticas y programas sociales”, Capital Social, cap. IV, Santiago de Chile, 2002.

COLEMAN, J. "Social Capital in the Creation of Human Capital", American Journal of Sociology. 94 (Supplement) S95-S120, 1988.

COLEMAN, James, Foundations of Social Theory. Belnap Press of Harvard University Press, Cambridge, 1990.

COFFEY, William J. e BAILY, Antoine S., "Producer Services and Systems of Flexible Production”, Urban Studies, 29 (6), August/1993, pp. 857-68.

CORIAT, B. Pensar pelo avesso. Rio de Janeiro: Revan, UFRJ, 1994. 
DASGUPTA, Partha e SERAGELDIN, Ismail Social capital: a Multiperspective Approach. Banco Mundial, Washington, 1998.

FUKUYAMA, F., "Trust: The Social Values and the Creation of Prosperity". New York Free Press, 1995.

GERSHUNY, J. I., "Post-Industrial Society: the Mith of the Service Economy", em Futures, 9 (2), April/1977: 103-14.

GERSHUNY, Jonathan. The New Service Economy: the transformation of employment in industrial societies, Westview Press, 1990.

GROOTAERT, Christiaan, “Social Capital: The Missing Link?” Social Capital Initiative Working Paper n. 3, The World Bank Social Development Family Environmentally and Socially Sustainable Development Network, Washington, 1998.

HILL, T.P., "On goods and services”, em Review of Income and Wealth, 23 (4), December/1977: 315-38.

KATOUZIAN, M. A ., "The Development of the Service Sector: A New Approach”, em Oxford Economic Papers, 22, 1970.

KLIGSBERG, Bernardo, "El rol del capital social y de la cultura en el processo de desarrollo", Capital social y cultura: claves estratégicas para el desarrollo, BID, Washington, 2000.

KNACK, S. e KEEFER, P. "Does Social Capital Have an Economic Payoff? A Cross-Country Investigation”. World Bank, Policy Research Department, Washington, 1996.

KON, Anita, A produção terciária, São Paulo. Nobel, 1992.

KON, Anita, Service Industries and Economic Development, University of Illinois at Urbana-Champaign/UIUC, Research Report, December, 1996.

KON, Anita, “Atividades terciárias: induzidas ou indutoras do desenvolvimento econômico?”, em Ferraz, J.C., Crocco, M. e Elias, L. A ., Liberalização econômica e desenvolvimento, São Paulo. Futura, 2003.

KON, Anita, Economia de serviços, Rio de Janeiro. Campus/Elseviere, 2004.

LECHNER, Norbert, "Desafíos de un desarrollo humano: individualización y capital social”. Em Insittuiciones y desarrollo, $\mathrm{N}^{\circ}$ 7, Instituto Internacional de Gobernabilidad, Chile, 2000.

MARSHALL, J. Neil e WOOD, Peter A., Services and Space: Key Aspects of Urban and Regional Development. Longman Group Limited, Harlow, England, 1995.

MELCHERT, Ricardo Ruiz, Micro e pequenas empresas formais: uma análise da contribuição à economia paulista nos anos 90. PUCSP, dissertação de Mestrado, São Paulo, 2003.

MIRANDA, Francisca e MONZÓ, Evelyn, Capital social, estrategias individuales y colectivas: el impacto de programas públicos en tres comunidades campesinas de Chile., CEPAL, Serie Políticas Sociales n. 67, Santiago de Chile, 2003.

NORTH, D. 1990. Institutions, Institutional Change, and Economic Performance. New York: Cambridge University Press.

OLSON, M. The Rise and Decline of Nations: Economic Growth, Stagflation, and Social Rigidities. New Haven: Yale University Press, 1982.

OCHEL, W. e WEGNER, M., Services Economy in Europe. Opportunities to Growth, Pinter, London, 1987.

PUTNAM, Robert, “The prosperous community: social capital and public life”, American Prospects, n. 13, 1993.

STANBACK, Thomas, Understanding the Service Economy, John Hopkings UP, Baltimore, 1979.

TOURAINE, A., La société post-industrielle, Denoel, Paris, 1969.

ONU, A System of National Accounts, Série F, n. 2 Revisão 3, New York, 1968.

WALKER, Richard A ., "Is There a Service Economy? The changing capitalist division of labor", em Science and Society, vol. XLIX, n. 1, Spring 1985: 42-83.

WOOLCOCK, Michael, "Social capital and economic development: toward a theoretical synthesis and policy framework", Theory and Society, n. 27, 1998. 